\title{
The Synthesis of Hydrobenzoin-Based Monoaza Crown Ethers and Their Application as Recyclable Enantioselective Catalysts
}

\author{
Tamás Nemcsok ${ }^{1}$ - Zsolt Rapi ${ }^{1}$. Péter Bagi ${ }^{1}$. Attila Oláh ${ }^{1}$ - György Keglevich ${ }^{1}$ · Péter Bakó ${ }^{1}$
}

Received: 17 July 2019 / Accepted: 15 October 2019 / Published online: 12 November 2019

(c) The Author(s) 2019

\begin{abstract}
New recyclable monoaza-15-crown ethers have been synthesized starting from $(R, R)-(+)$ - and $(S, S)-(-)$-hydrobenzoin. These macrocycles proved to be efficient and reusable phase transfer catalysts in a few asymmetric reactions under mild conditions. The asymmetric epoxidation of trans-chalcone took place with up to $81 \%$ ee, while using other chalcone derivatives, the products were formed with $68-88 \%$ ee. The hydrobenzoin-based lariat ethers were also tested in the cyclopropanation of a few electron deficient olefins using diethyl bromomalonate to afford the product with good enantioselectivities (54-75\% ee). The catalysts were recovered by salt formation, followed by extraction, and were reused without the loss of the activity and effect on the enantioselectivity.
\end{abstract}

\section{Graphic Abstract}

The synthesis of hydrobenzoin-based monaza crown ethers and their application as recyclable enantioselective catalysts.

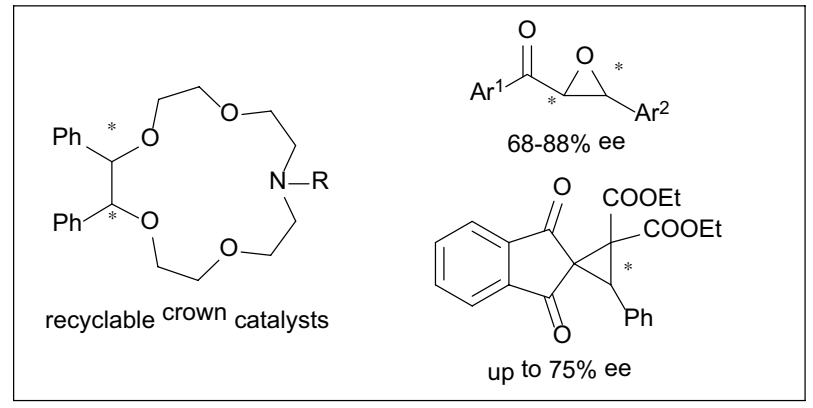

\section{Introduction}

Asymmetric phase transfer catalysis has become a topic of great scientific interest in the last 30 years. A great number of chiral catalysts have been synthesized and used with excellent enantioselectivities in different reactions [1-8]. Despite all advantages, most of the applied methods have the

Electronic supplementary material The online version of this article (https://doi.org/10.1007/s10562-019-03013-0) contains supplementary material, which is available to authorized users.

Péter Bakó

pbako@mail.bme.hu

1 Department of Organic Chemistry and Technology, Budapest University of Technology and Economics, PO Box 91, 1521 Budapest, Hungary shortcomings that the recovery of the catalyst is not solved, or cumbersome purification (e.g. chromatography) has to be used. Recently, in response to economy and sustainability concerns, an increasing attention has been paid to process intensification, elimination of harmful substances, waste reduction, and recycling of the solvents and catalysts. Therefore, the design of recyclable chiral phase transfer catalyst is a challenging area in current organic chemistry. For this purpose, several polymer-supported chiral ammonium salt-type catalysts derived mostly from cinchona alkaloids have been synthesized [9-16]. However, the enantioselectivity achieved by most of these catalysts decreased as compared to the nonsupported derivatives. To avoid this decrease in the selectivity, a few recyclable homogenous catalysts have also been developed. A binaphthyl-based fluorous phase transfer catalyst has been used 
by Maruoka et al. in the synthesis of a few amino acids with high enantioselectivities [17]. This fluorinated catalyst was regenerated by extraction with a fluorous solvent, however, the scale up of this method is problematic due to the high price of the fluorinated reagents and solvents. Nájera et al. applied a cinchona-derived dimeric ammonium salt that provided a good enantioselectivity, and it was possible to recover the catalyst almost quantitatively by precipitation in ether [18].

Chiral crown ethers have also been used in enantioselective syntheses as phase transfer catalysts [19]. Macrocycles derived from binaphtol, [20, 21] carbohydrates, [22-26] spirobiindane [27] and other chiral diols [28-31] have all been used efficiently in different asymmetric reactions. In our group, monoaza-15-crown-5-type lariat ethers incorporating a carbohydrate unit were synthesized $[32,33]$. These macrocycles generated high asymmetric induction in certain model reactions [34-37]. Although chiral crown compounds have been widely used as phase transfer catalysts, to the best of our knowledge, none of these catalysts were reusable. Monoaza crown ethers have the advantage that they can be regenerated by salt formation, followed by extraction. This recovery technique is known for achiral monoaza crown ethers [38]. Our most efficient monoaza-type catalysts all had acid sensitive functional groups, therefore, this type of recovery attempt has not been successful so far. We intended to develop new chiral crown ether catalysts, which can be recovered by the simple method mentioned.

Herein, we wish to report the synthesis and application of a few recyclable hydrobenzoin-based monoaza-15-crown-5 ethers. Enantiopure $(R, R)$ - and $(S, S)$-hydrobenzoin have been extensively used in asymmetric syntheses as chiral ligands, auxiliaries, and chiral building blocks because of their easy availability and relatively low price, as compared to other chiral diols [39] We assumed that a diol with bulky aromatic groups would be the best choice as a starting material, since both steric and $\pi$ - $\pi$ interactions may enhance the enantioselectivity of the catalyst. Crown ethers derived from hydrobenzoin have already been reported [40]. These macrocycles generated good enantioselectivites in the asymmetric reduction of aromatic ketones with ammonia-borane complexes [30, 31], but only moderate results were obtained in a Michael addition [29]. As monoaza-type crown ethers starting from hydrobenzoin have not been prepared so far, we intended to synthesize a few such derivatives, with various side arms, and test their catalytic effect, and also their reusability.

\section{Results and Discussion}

\subsection{Synthesis of Hydrobenzoin-Based Lariat Ethers}

The synthesis of monoaza-15-crown ethers was performed according to the protocol elaborated earlier, starting from
$(R, R)$ - and $(S, S)$-hydrobenzoin (Scheme 1) [41, 42]. The vicinal hydroxy groups of diol 1 were alkylated with bis(2chloroethyl) ether in the presence of $50 \% a q . \mathrm{NaOH}$ and tetrabutylammonium hydrogensulphate to give intermediates $(R, R)-\mathbf{2}$ and $(S, S)-\mathbf{2}$ in $64 \%$ and $68 \%$ yield after chromatography. The exchange of chlorine to iodine in bischloro compounds $(R, R)-\mathbf{2}$ and $(S, S)-\mathbf{2}$ was accomplished by reaction with $\mathrm{NaI}$ in boiling acetone in excellent yields (93\% and $95 \%$, respectively). Bisiodo compound $(R, R)-3$ was then cyclized with four different amines (3-aminopropan1-ol, 3-methoxypropylamine, 2-(2-methoxyphenyl)ethylamine and 2-(3,4-diethoxyphenyl)ethylamine, respectively) in boiling acetonitrile in the presence of $\mathrm{Na}_{2} \mathrm{CO}_{3}$ to afford azacrown ethers $(R, R)$-4a-d after chromatography in yields of $52-68 \%$. Previously, these side arms proved to be efficient in terms of enantioelectivity when they were attached to carbohydrate-based monoaza crown ethers [43, 44]. The $(S, S)$-3 intermediate was reacted only with 3-aminopropan1-ol and 2-(3,4-diethoxyphenyl)ethylamine, because these two side chains proved to be the most effective according to experiments with macrocycles $(R, R)-\mathbf{4 a - d}$. Thus, six new hydrobenzoin-based monoaza crown ethers have been synthesized, of which $(S, S)-\mathbf{4 a}$ and $(R, R)-\mathbf{4 a}$ and also $(S, S)-\mathbf{4} \mathbf{c}$ and $(R, R)-\mathbf{4} \mathbf{c}$ are pairs of enantiomers, therefore the outcome of the asymmetric reactions may be influenced by choosing the proper enantiomer of the catalyst.

\subsection{Asymmetric Reactions Catalyzed by Lariat Ethers}

The new hydrobenzoin-based catalysts were applied in a few asymmetric reactions to test their ability to induce enantioselectivity. Besides synthesizing the products in high optical purity, we also tried to turn these model reactions more eco-friendly by choosing green solvents, using minimum amounts of the reagents and catalyst, and by recycling the catalyst after the reactions. The crude products were purified by preparative TLC. Enantiomeric excess of the products was determined by chiral HPLC analysis.

One of the model reactions was the asymmetric epoxidation of trans-chalcone (5a) and its derivatives. Chiral epoxides are useful intermediates in organic synthesis, prone to react with a variety of nucleophilic reagents affording intermediates and precursors in the preparation of enantiomerically pure bioactive compounds [45-48]. Although the asymmetric synthesis of epoxides $\mathbf{6}$ was reported applying different catalysts $[49,50]$, only a part of these methods used a recyclable catalyst [51-54], and even less examples can be found, when the activity of the catalyst did not decrease after the recyclings [55-57].

First, we tested the new hydrobenzoin-based catalysts $(R, R)$-4a-d under the reaction conditions reported by our group using carbohydrate-based crown ethers [58] with 
Scheme 1 The synthesis of hydrobenzoin-based crown ethers $((R, R)-\mathbf{4 a}-\mathbf{d},(S, S)-\mathbf{4 a}$ and $(S, S)-\mathbf{4 c})$
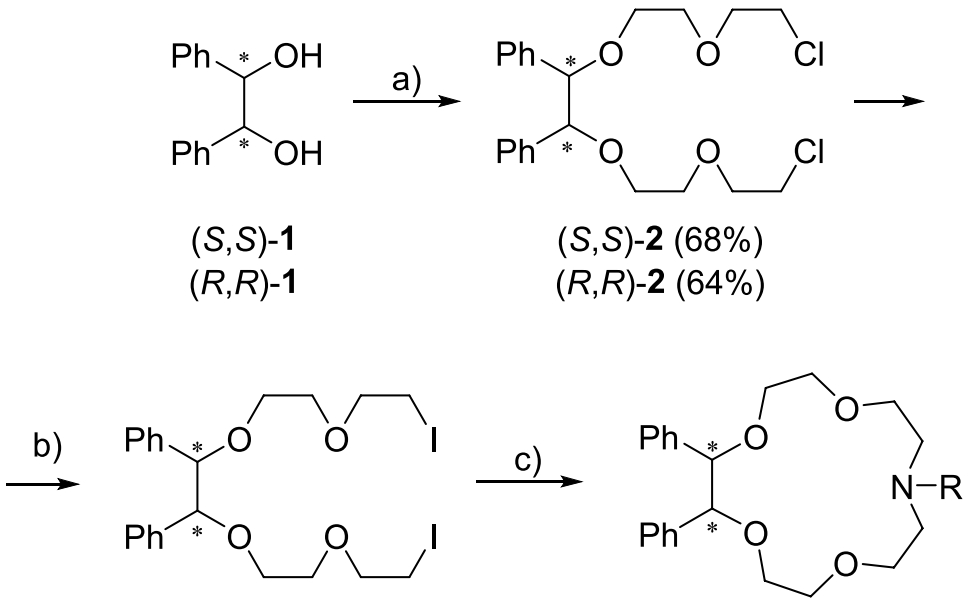

$(S, S)-3(95 \%)$

$(S, S)-4 \mathrm{a} \mathrm{R}=\left(\mathrm{CH}_{2}\right)_{3} \mathrm{OH}(61 \%)$

$(R, R)-4 \mathrm{a} \mathrm{R}=\left(\mathrm{CH}_{2}\right)_{3} \mathrm{OH}(68 \%)$

$(R, R)-4 \mathrm{~b} \mathrm{R}=\left(\mathrm{CH}_{2}\right)_{3} \mathrm{OMe}(63 \%)$

$(\mathrm{S}, \mathrm{S})-\mathbf{4 c} \mathrm{R}=\left(\mathrm{CH}_{2}\right)_{2}-3,4-(\mathrm{OEt})_{2} \mathrm{C}_{6} \mathrm{H}_{3}(58 \%)$

$(R, R)-4 \mathrm{c} \mathrm{R}=\left(\mathrm{CH}_{2}\right)_{2}-3,4-(\mathrm{OEt})_{2} \mathrm{C}_{6} \mathrm{H}_{3}(62 \%)$

$(R, R)-4 \mathrm{~d} \mathrm{R}=\left(\mathrm{CH}_{2}\right)_{2}-2-\mathrm{OMeC}_{6} \mathrm{H}_{3}(52 \%)$

a) $\left(\mathrm{ClCH}_{2} \mathrm{CH}_{2}\right)_{2} \mathrm{O}, 50 \%$ aq. $\mathrm{NaOH}, \mathrm{Bu}_{4} \mathrm{NHSO}_{4}$, rt; b) $\mathrm{Nal}$, acetone, reflux;

c) 3-aminopropan-1-ol, 3-methoxypropylamine, 2-(2-methoxyphenyl)ethylamine or 2-(3,4-diethoxyphenyl)ethylamine, anhydrous $\mathrm{Na}_{2} \mathrm{CO}_{3}, \mathrm{CH}_{3} \mathrm{CN}$, Ar, reflux.

some modifications (Table 1, entries 1-4). Less catalyst (5 mol\%), and only 1.3 equivalents of the oxidizing agent (tert-butylhydroperoxide) were used in a toluene-20\% aq. $\mathrm{NaOH}$ two phase system. Other oxidizing agents such as $\mathrm{H}_{2} \mathrm{O}_{2}, \mathrm{NaOCl}$ and $m$ CPBA were tested earlier, however, the enantioselectivities and/or the yields were significantly lower as compared to $t \mathrm{BuOOH}$. Among catalysts $(R, R)$ 4a-d, only crown ether $(R, R)$-4a with hydroxypropyl side arm generated a significant asymmetric induction ( $80 \%$ ee). Using the other three derivatives $((R, R)-\mathbf{4 b}-\mathbf{d})$, product $\mathbf{6 a}$

Table 1 Optimization of the reaction conditions and screening the catalyst in the asymmetric epoxidation of trans-chalcone (5a)<smiles>O=C(/C=C/c1ccccc1)c1ccccc1</smiles>

$5 a$ solvent

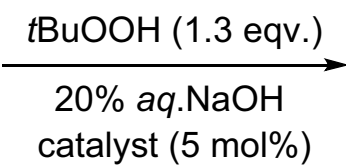
catalyst (5 mol\%)<smiles>C[C@@]1(C(=O)c2ccccc2)O[C@@H]1c1ccccc1</smiles>

$6 a$

\begin{tabular}{lllllll}
\hline Entry & Catalyst & Time $(\mathrm{h})$ & Solvent & $\mathrm{T}\left({ }^{\circ} \mathrm{C}\right)$ & Yield $(\%)$ & ee $(\%)^{\mathrm{a}}$ \\
\hline 1 & $(R, R)-\mathbf{4 a}$ & 4 & Toluene & 25 & 89 & $80(2 S, 3 R)$ \\
2 & $(R, R)-\mathbf{4 b}$ & 4 & Toluene & 25 & 81 & $15(2 S, 3 R)$ \\
3 & $(R, R)-\mathbf{4 c}$ & 5 & Toluene & 25 & 90 & $8(2 S, 3 R)$ \\
4 & $(R, R)-\mathbf{4 d}$ & 6 & Toluene & 25 & 85 & $6(2 S, 3 R)$ \\
5 & $(R, R)-\mathbf{4 a}$ & 5 & $\mathrm{CH}_{2} \mathrm{Cl}_{2}$ & 25 & 81 & $76(2 S, 3 R)$ \\
6 & $(R, R)-\mathbf{4 a}$ & 5 & $\mathrm{Et}_{2} \mathrm{O}$ & 25 & 83 & $81(2 S, 3 R)$ \\
7 & $(R, R)-\mathbf{4 a}$ & 4 & $\mathrm{MTBE}$ & 25 & 82 \\
8 & $(R, R)-\mathbf{4 a}$ & 10 & $\mathrm{MTBE}$ & 0 & 83 & $79(2 S, 3 R)$ \\
9 & $(S, S)-\mathbf{4 a}$ & 4 & MTBE & 25 & 90 & \\
\hline
\end{tabular}

${ }^{a}$ Based on chiral HPLC, the absolute configuration was assigned by comparison of the specific rotations with literature data [59] 
was obtained with low enantioselectivities (6-15\%). In all cases complete diastereoselectivity was observed. The significant difference between the catalytic activities is currently unclear. Similar phenomenon has been observed earlier in the case of other crown compounds when catalysts with hydroxypropyl side chain performed better than their methoxypropyl analogues [33, 37, 43].

Thereafter, we tested the influence of different solvents using catalyst $(R, R)-\mathbf{4 a}$ (Table 1 , entries 5-7). In dichloromethane, the enantioselectivity was lower $(56 \%)$, while the experiments carried out in diethyl ether or methyl tertbutyl ether (MTBE) led to similar results (77\% ee and $81 \%$ ee, respectively) obtained in toluene ( $80 \%$ ee). The yield of epoxyketone 6a was not significantly influenced by the solvent. Considering the green chemical principles, MTBE was chosen as the solvent in the next experiments. Finally, we investigated the effect of the temperature on the course of the reaction (Table 1, entry 8). When the reaction was performed at $0{ }^{\circ} \mathrm{C}$, an increased reaction time of $10 \mathrm{~h}$ (instead of $4 \mathrm{~h}$ ) was needed, but this change did not increase the enantioselecivity $(81 \%)$. Using the other enantiomer $(S, S)$ of catalyst 4a, almost the same enantiomeric excess (79\%) was observed, but, as expected, this occasion the other enantiomer $(2 R, 3 S)$ of the product was formed (Table 1, entry 9).

After exploring the optimized protocol for the enantioselective epoxidation, we investigated the generality and the scope of this methodology. The oxidation of a variety of chalcone derivatives with different substituents $\left(\mathrm{Ar}^{1}\right.$ or $\mathrm{Ar}^{2}$ ) in the aromatic rings (5b-k) were studied (Table 2).
It can be concluded from Table 2 that neither the yield (71-93\%), nor the enantioselectivity (68-88\% ee) changed drastically, and in a few cases even slightly better results were obtained as compared to those observed with the unsubstituted chalcone ( $88 \%$ yield, $81 \%$ ee). The chlorosubstituted products were formed in good yields and with $70-88 \%$ ee (Table 2 , entries $1-5$ ). The degree of asymmetric induction was slightly influenced by the position of the chlorine atom in the phenyl ring $\left(\mathrm{Ar}^{2}\right)$. When the $\mathrm{Cl}$ atom was in ortho position, the enantioselectivity was somewhat lower (6b: $75 \%$ ee, $\mathbf{6 e}: 70 \%$ ee) as compared to the meta and para substituted derivatives (6c: $85 \%$ ee, $\mathbf{6 d}$ : $83 \%$ ee). The highest enantioselectivity ( $88 \%$ ee) was observed in case of product $\mathbf{6 f}$, when the $\mathrm{Cl}$ atom was in the other phenyl ring $\left(\mathrm{Ar}^{1}\right)$ in para position. The methyl group did not have an influence on the outcome of the reaction (Table 2, entries 6, 7). Product $6 \mathrm{~g}\left(\mathrm{Ar}^{1}=\mathrm{Ph}, \mathrm{Ar}^{2}=3-\mathrm{Me}-\mathrm{C}_{6} \mathrm{H}_{4}\right)$ and 6h $\left(\mathrm{Ar}^{1}=4-\mathrm{Me}-\mathrm{C}_{6} \mathrm{H}_{4}, \mathrm{Ar}^{2}=\mathrm{Ph}\right)$ were both formed with $79 \%$ ee. The experiment with para nitro substituted chalcone $5 \mathbf{i}\left(\mathrm{Ar}^{2}=4-\mathrm{NO}_{2}-\mathrm{C}_{6} \mathrm{H}_{4}\right)$ resulted with an ee value of $74 \%$ (Table 2, entry 8 ). Somewhat weaker enantioselectivity $(68 \%)$ was observed in case of chalcone $5 \mathbf{j}\left(\mathrm{Ar}^{1}=\mathrm{Ph}\right.$, $\mathrm{Ar}^{2}=$ piperonyl) (Table 2, entry 9). The enantioselective epoxidation catalyzed by $(R, R)-\mathbf{4 a}$ was also performed with the structurally similar, but cyclic 2-benzylidene1-indanone (5k) and 2-benzylidene-1-tetralone (5l). High enantiomeric excess $(86 \%)$ was observed in case of the oxidation of 2-benzylidene-1-tetralone (51), while the experiment with 2-benzylidene-1-indanone (5k) led to

Table 2 Generality of catalyst $(R, R)-\mathbf{4 a}$ in the asymmetric epoxidation of chalcone derivatives $(\mathbf{5 b}-\mathbf{m})$

\begin{tabular}{|c|c|c|c|c|c|}
\hline \multirow[b]{2}{*}{ Entry } & \multirow[b]{2}{*}{$\mathrm{Ar}^{1}$} & \multirow{2}{*}{$\begin{array}{c}\mathrm{MTBE} \\
\underset{\mathrm{tBuOOH}(1.3 \text { eqv. })}{\longrightarrow} \\
\underset{(R, R)-4 a \text { aq }(5 \mathrm{NaOH}}{(} \mathrm{mol}) \\
\\
\mathrm{Ar}^{2}\end{array}$} & $\mathrm{Ar}^{1} \underbrace{\mathrm{Ob}-\mathrm{n}}_{*}$ & $r^{2}$ & \multirow[b]{2}{*}{ ee $(\%)^{\mathrm{a}}$} \\
\hline & & & Time (h) & Yield (\%) & \\
\hline 1 & $\mathrm{C}_{6} \mathrm{H}_{5}$ & $2-\mathrm{Cl}-\mathrm{C}_{6} \mathrm{H}_{4}$ & 10 & 6b: 76 & $75(2 S, 3 R)$ \\
\hline 2 & $\mathrm{C}_{6} \mathrm{H}_{5}$ & $3-\mathrm{Cl}-\mathrm{C}_{6} \mathrm{H}_{4}$ & 7 & 6c: 88 & $85(2 S, 3 R)$ \\
\hline 3 & $\mathrm{C}_{6} \mathrm{H}_{5}$ & 4-Cl- $\mathrm{C}_{6} \mathrm{H}_{4}$ & 5 & 6d: 93 & $83(2 S, 3 R)$ \\
\hline 4 & $\mathrm{C}_{6} \mathrm{H}_{5}$ & 2,6-diCl- $\mathrm{C}_{6} \mathrm{H}_{3}$ & 3 & 6e: 85 & $70(-)$ \\
\hline 5 & 4-Cl- $\mathrm{C}_{6} \mathrm{H}_{4}$ & $\mathrm{C}_{6} \mathrm{H}_{5}$ & 5 & 6f: 89 & $88(2 S, 3 R)$ \\
\hline 6 & $\mathrm{C}_{6} \mathrm{H}_{5}$ & 3-Me- $\mathrm{C}_{6} \mathrm{H}_{4}$ & 6 & 6g: 79 & $79(2 S, 3 R)$ \\
\hline 7 & 4-Me- $\mathrm{C}_{6} \mathrm{H}_{4}$ & $\mathrm{C}_{6} \mathrm{H}_{5}$ & 8 & 6h: 86 & $79(2 S, 3 R)$ \\
\hline 8 & $\mathrm{C}_{6} \mathrm{H}_{5}$ & $4-\mathrm{NO}_{2}-\mathrm{C}_{6} \mathrm{H}_{4}$ & 24 & 6i: 80 & $74(2 S, 3 R)$ \\
\hline 9 & $\mathrm{C}_{6} \mathrm{H}_{5}$ & Piperonyl & 10 & 6j: 86 & $68(+)$ \\
\hline 10 & 2-benzylidene-1-indanone & & 24 & 6k: 71 & $76(+)$ \\
\hline 11 & 2-benzylidene-1-tetralone & & 24 & 61: 75 & $86\left(2 S, 3^{\prime} R\right)$ \\
\hline
\end{tabular}

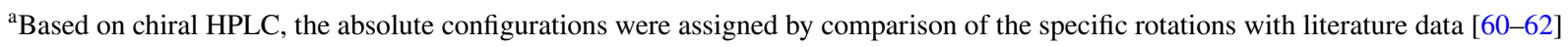


somewhat lower selectivity ( $76 \%$ ee) (Table 2 , entries 11 , 12).

The reusability of catalyst $(R, R)-\mathbf{4 a}$ was also investigated in the epoxidation of chalcone 5a. The recovery technique was summarized in Scheme 2. After completion of the reactions, the monoaza crown ether $(R, R)-\mathbf{4 a}$ was transformed to its hydrochloride salt with $10 \% a q$. $\mathrm{HCl}$, and extracted several times with $\mathrm{HCl}$ solution. Then, sodium hydroxide was added to the aqueous layer until the $\mathrm{pH}$ turned basic $\mathrm{pH}$ 8-9), and the liberated azacrown ether was extracted with MTBE. Finally, the organic layer was concentrated, and the catalyst was dried in a desiccator for $24 \mathrm{~h}$. The recovered catalyst was then reused in the next experiment.

The results of the repeated uses are summarized in Table 3, from which one can see that neither the enantioselectivity (78-81\%) nor the yields (86-90\%) changed much even after the fifth cycle. Applying the above-mentioned method, catalyst $(R, R)-\mathbf{4 a}$ was recovered with good yields (95-98\%) and high purity (checked by ${ }^{1} \mathrm{H}$ NMR). The slight loss of the catalyst was compensated with the addition of unused $(R, R)-\mathbf{4 a}$.

Thereafter, the hydrobenzoin-based crown compounds (4) were tested in some MIRC (Michael-initiated ring closure) reactions, in which an electron deficient olefin reacts with diethyl bromomalonate (8) affording cyclopropane derivatives. Chiral cyclopropanes are prevalent in natural products and bioactive compounds [63-66]. Moreover, they can be easily transformed to other important optically active compounds as the consequence of the easy ring cleavage of the strained cyclopropane moiety [67-69]. Recently, much attention was payed to the enantioselective synthesis of cyclopropanes, [70-72] however, only a few of the reported methods applied chiral phase transfer catalysts [73-77].

First, the reaction conditions were optimized, and the effect of catalysts was evaluated. The MIRC reaction of 2-benzylidene-1,3-indandione (7) and diethyl bromomalonate (8) was chosen as the model reaction to test the utility of catalysts $(R, R)-\mathbf{4 a - d}$ (Table 4 , entries $1-4)$ [78, 79]. The reactions took place in diethyl ether using $\mathrm{Na}_{2} \mathrm{CO}_{3}$ as the base, and $5 \mathrm{~mol} \%$ of the catalyst in $1-2 \mathrm{~h}$. In this instance, the side arm of lariat ethers $(R, R)-\mathbf{4 a}-\mathbf{d}$ did not have a significant effect on the enantioselectivity as compared to the above-mentioned epoxidation. Product 9, with
Table 3 Recycling of catalyst $(R, R)-\mathbf{4 a}$ in the asymmetric epoxidation of trans-chalcone (5a)

\begin{tabular}{llllll}
\hline Number of uses & 1 & 2 & 3 & 4 & 5 \\
\hline Yield (\%) & 87 & 89 & 88 & 90 & 86 \\
ee $(\%)^{\mathrm{a}}$ & 80 & 81 & 81 & 78 & 81 \\
\hline
\end{tabular}

${ }^{\mathrm{a}}$ Based on chiral HPLC

$S$ configuration in all cases, was formed with moderate enantioselectivities (55-63\%), and in good yields (74-83\%) regardless of the side chain. The best result was obtained using crown ether $(R, R)-\mathbf{4 c}$ with a 3,4-diethoxyphenethyl side arm (Table 4 , entry 3 ), therefore the further experiments were carried out with this catalyst. Next, the effect of the solvent was investigated (Table 4, entry 5-9). After testing six different solvents, it may be concluded that the nature of the solvent has a strong influence on the asymmetric induction. Ether type solvents $\left(\mathrm{Et}_{2} \mathrm{O}\right.$ and MTBE) proved to be the best (63\% and 64\% ee), whereas in dichloromethane, hexane or ethyl acetate, the enantioselectivities were much lower (30\%, $40 \%$ and $44 \%$, respectively). However, the yield of cyclopropane 9 did not depend much on the different solvents (78-86\%). Again, considering green chemical principles, MTBE was chosen for further investigations.

Eventually, the reaction was performed at $0{ }^{\circ} \mathrm{C}$ (Table 4, entry 10), resulting in spiro compound 9 with a better enantiomeric excess (75\%). Carrying out the reaction at $-20^{\circ} \mathrm{C}$ the conversion remained incomplete (Table 4 , entry 11 ). While in the presence of lariat ether $(R, R)-\mathbf{4} \mathbf{c}$ the $S$ isomer of cyclopropane derivative 9 was formed in $75 \%$ ee, catalyst $(S, S)-\mathbf{4} \mathbf{c}$ induced the formation of the opposite $R$ isomer with almost the same enantiomeric excess (72\%). This methodology seems to be superior as compared to the previously reported synthetic method of compound 9, [77-79] since less catalyst was used $(5 \mathrm{~mol} \%$ instead of $10 \mathrm{~mol} \%$ and $50 \mathrm{~mol} \%$ ), slightly better ee values were observed, and the recovery of the catalyst may be solved.

After the cyclopropanation of starting material 7, the recovery of catalyst $\mathbf{4 c}$ was also investigated using the above described method. The experiment was repeated five times with the recovered catalyst (the loss was compensated), and the results confirmed that macrocycle $\mathbf{4 c}$ can
Scheme 2 Recovery of catalyst $(R, R)$-4a by salt formation followed by extraction

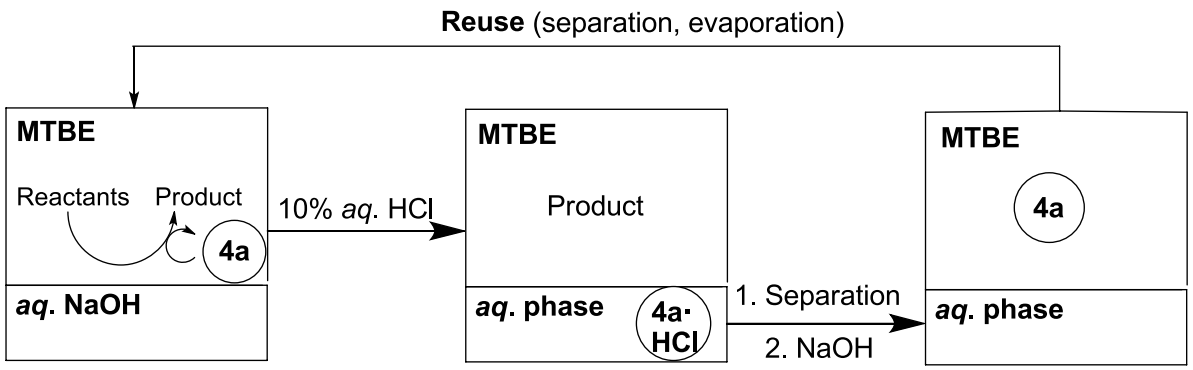


Table 4 Optimization of the reaction conditions and screening the catalyst in the asymmetric MIRC reaction of 2-benzylidene-1,3-indandione (7) and diethyl bromomalonate (8)<smiles>CCOC(=O)C(Br)C(=O)OCC</smiles>

7
8<smiles>CCOC(=O)C1(C(=O)OCC)C(c2ccccc2)C12C(=O)c1ccccc1C2=O</smiles>

9

\begin{tabular}{lllllll}
\hline Entry & Catalyst & Solvent & $\mathrm{T}\left({ }^{\circ} \mathrm{C}\right)$ & Time $(\mathrm{h})$ & Yield $(\%)$ & ee $(\%)^{\mathrm{a}}$ \\
\hline 1 & $(R, R)-\mathbf{4 a}$ & $\mathrm{Et}_{2} \mathrm{O}$ & 25 & 2 & 83 & $58(S)$ \\
2 & $(R, R)-\mathbf{4 b}$ & $\mathrm{Et}_{2} \mathrm{O}$ & 25 & 2 & 81 & $55(S)$ \\
3 & $(R, R)-\mathbf{4 c}$ & $\mathrm{Et}_{2} \mathrm{O}$ & 25 & 1 & 80 & $63(S)$ \\
4 & $(R, R)-\mathbf{4 d}$ & $\mathrm{Et}_{2} \mathrm{O}$ & 25 & 1 & 74 & $58(S)$ \\
5 & $(R, R)-\mathbf{4 c}$ & $\mathrm{CH}_{2} \mathrm{Cl}_{2}$ & 25 & 2 & 81 & $30(S)$ \\
6 & $(R, R)-\mathbf{4 c}$ & toluene & 25 & 3 & 78 & $55(S)$ \\
7 & $(R, R)-\mathbf{4 c}$ & EtOAc & 25 & 2 & 86 & $44(S)$ \\
8 & $(R, R)-\mathbf{4 c}$ & hexane & 25 & 6 & 78 & $40(S)$ \\
9 & $(R, R)-\mathbf{4 c}$ & MTBE & 25 & 1 & 82 & $64(S)$ \\
10 & $(R, R)-\mathbf{4 c}$ & MTBE & 0 & 3 & 83 & $75(S)$ \\
11 & $(R, R)-\mathbf{4 c}$ & MTBE & -20 & 24 & 28 & $78(S)$ \\
12 & $(S, S)-\mathbf{4 c}$ & MTBE & 0 & 3 & 81 & $72(R)$ \\
\hline
\end{tabular}

${ }^{a}$ Based on chiral HPLC, the absolute configuration was assigned by comparison of the specific rotations with literature data [78]

be reused without any decrease in its activity or selectivity. Product 9 was obtained in a yield of $75-84 \%$ and with an ee of $71-75 \%$. At the same time, the yield of the recovery was somewhat lower (73-83\%) for catalyst $\mathbf{4 c}$ as compared to species $\mathbf{4 a}$, that can be explained by the higher lipophilicity of macrocycle $\mathbf{4 c}$.

Having the optimized reaction conditions in hand, additional, less studied MIRC reactions were performed [77, 80, 81]. Electron deficient olefins $\mathbf{1 0 a - c}$ were reacted with diethyl bromomalonate (8) using both enantiomers of catalyst $\mathbf{4 c}$ to afford chiral cyclopropanes 11a-c (Table 5). The reactions were complete within one day $(5-24 \mathrm{~h})$, and the products were isolated in good yields (86-94\%) and with moderate enantioselectivities (54-72\%). The best result $(72 \%$ ee) was achieved in the cyclopropanation of ethyl $(E)$ 2-cyano-3-phenylacrylate (10b) (Table 5, entries 2 and 5). The corresponding product (11b) was obtained in a somewhat lower enantiomeric excess $(72 \%)$ than reported by Feng et al. (89\% ee) [81], however, in our method less catalyst was used (5 mol \% instead of $10 \mathrm{~mol} \%$ ), furthermore, the hydrobenzoin-based catalyst may be recycled, thus, this methodology is more robust.

Slightly lower enantioselectivities were observed in the reaction of benzylidenemalononitrile (10a) and $(E)$-3-phenyl-2-(phenylsulfonyl)acrylonitrile (10c) (59\% and 54\%, respectively). Both lower and higher enantioselectivities were reported earlier for the preparation of compound 11a $[36,77]$. A $80 \%$ ee was described by Cobb et al. for the synthesis of the dimethyl analogue of product 11c [80]. However, in these cases, the catalyst could not be reused; moreover, halogenated solvents, or solvent mixtures were used, that make these methods less valuable from the point of view of scaling up. Using the appropriate catalyst $((S, S)-\mathbf{4 c}$ or $(R, R)-\mathbf{4} \mathbf{c})$, the desired enantiomer of the product could be prepared with approximately the same enantiomeric excess and yield.

\section{Conclusions}

In conclusion, new hydrobenzoin-based monoaza-15-crown-5 ethers with various side arms have been synthesized, and applied as recyclable phase transfer catalysts in a few asymmetric reactions. To the best of our knowledge, this is the first time that a chiral crown ether phase transfer catalyst was reused in an efficient way. For the epoxidation of trans-chalcone, a scalable and green method was elaborated using recyclable catalyst $\mathbf{4 a}$ and MTBE as the solvent. The product was formed with good yield (90\%) and enantiomeric excess (81\%). Macrocycle 4a was reused five times without any decrease in 
Table 5 Asymmetric MIRC reaction of electron deficient olefins 10a-c and diethyl bromomalonate (8) using catalyst $\mathbf{4 c}$

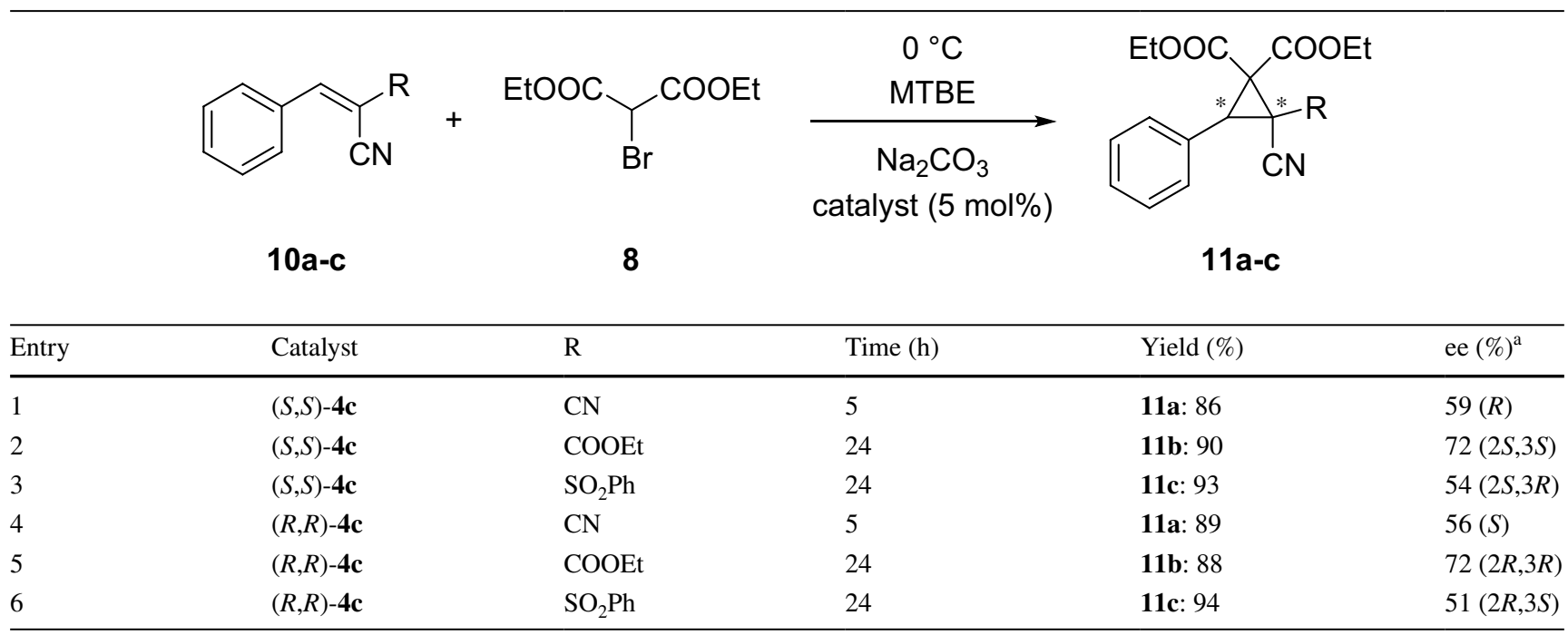

${ }^{a}$ Based on chiral HPLC, the absolute configuration was assigned by comparison of the specific rotations with literature data [77, 81] The absolute configuration of 11c was determined based on analogy with the dimethyl analogue [80]

the yield and enantioselectivity. The method developed has a general value, as it could be extended also to other chalcone derivatives. Neither the yield (71-93\%), nor the enantiomeric excess $(68-86 \%)$ of the products decreased drastically by the effect of the substituents in the aromatic ring of the chalcone. In the asymmetric MIRC reaction of 2-benzylidene-1,3-indandione, crown ether $\mathbf{4} \mathbf{c}$ with a 3,4-diethoxyphenylethyl side arm generated the highest enantiomeric excess (75\%). The experiments with benzylidenemalonitrile, ethyl (E)-2-cyano3-phenylacrylate, $(E)$-3-phenyl-2-(phenylsulfonyl)acrylonitrile resulted in good yields (85-94\%) and moderate ee values (54-72\%). This methodology for the synthesis of these chiral cyclopropanes seems to be superior from the point of view green chemistry and scaling up, as compared to previously reported methods. These promising results encourage us to perform further investigations with the hydrobenzoin-based crown ethers by substituting the aromatic ring of hydrobenzoin. We hope that these modifications will improve the selectivity of our catalysts, and even enantiopure products may be obtained. We believe that the applied recovery technique can help to expand the sphere of application of chiral monoaza crown ethers in asymmetric catalysis by eliminating the drawback regarding the high price and poor recyclability.

\section{Experimental}

\subsection{General Procedure for Preparation of Bischloro Compounds $(R, R)-2$ and $(S, S)-2$}

A solution of hydrobenzoin $(R, R-\mathbf{1}$ or $S, S-\mathbf{1})$ and tetrabutylammonium hydrogensulphate in bis(2-chloroethyl)ether was vigorously stirred with $50 \% a q$. $\mathrm{NaOH}$ solution at room temperature for $10 \mathrm{~h}$. Then, the mixture was poured on a mixture of $\mathrm{CH}_{2} \mathrm{Cl}_{2}$ and water 1:1 (3 times the volume of the reaction mixture), and the phases were separated. The water layer was extracted twice with $\mathrm{CH}_{2} \mathrm{Cl}_{2}$, the combined organic layer was washed with water, and dried $\left(\mathrm{Na}_{2} \mathrm{SO}_{4}\right)$, then the solvent was evaporated. The remaining bis(2-chloroethyl)ether was removed by vacuum distillation. The crude product was purified by column chromatography on silica gel to give the pure product.

\subsection{General Procedure for Preparation of Bisiodo Compounds $(R, R)-3$ and $(S, S)-3$}

A mixture of bischloro compound and $\mathrm{NaI}$ (4 equivalent) in dry acetone was stirred under reflux for $40 \mathrm{~h}$. After cooling, the precipitate was filtered, and washed with acetone. The combined acetone solutions were evaporated in vacuum. The residue was dissolved in a mixture of $\mathrm{CHCl}_{3}$ and water (1:1), the layers were separated, and the organic phase was washed with water and dried $\left(\mathrm{Na}_{2} \mathrm{SO}_{4}\right)$. Evaporation of the solvent afforded the products.

\subsection{General Procedure for the Preparation of Crown Ethers 4a-d}

Bisiodo podand $(R, R)-\mathbf{3}$ or $(S, S)-\mathbf{3}$ was dissolved in dry $\mathrm{CH}_{3} \mathrm{CN}$ and anhydrous $\mathrm{Na}_{2} \mathrm{CO}_{3}$ (6 equivalent), and the appropriate amine (1 equivalent) was added under Ar. The mixture was refluxed for $50 \mathrm{~h}$. Then, the solvent was removed, the residue was dissolved in a mixture of $\mathrm{CHCl}_{3}$ and water, the layers were separated, and the organic phase 
was washed with water, dried, then concentrated. The crude product was purified by column chromatography.

\subsection{General Procedure for the Asymmetric Epoxidations}

trans-Chalcone derivative $(0.5 \mathrm{mmol})$ and crown catalyst ( $5 \mathrm{~mol} \%$ ) were dissolved in MTBE (3 ml), then $0.12 \mathrm{ml}(1.3$ equivalent) tert-butylhydroperoxide (5.5 $\mathrm{M}$ in decane) and $20 \% a q$. $\mathrm{NaOH}$ solution $(1 \mathrm{ml})$ were added. The mixture was stirred at room temperature. The reactions were monitored by TLC (hexane-ethyl-acetate 10:2). After completion, the mixture was diluted with MTBE $(7 \mathrm{ml})$ and water $(3 \mathrm{ml})$, and the phases were separated. The organic layer was washed with $10 \%$ aq. $\mathrm{HCl}$ solution $(3 \times 10 \mathrm{ml})$, dried $\left(\mathrm{Na}_{2} \mathrm{CO}_{3}\right.$ and $\mathrm{Na}_{2} \mathrm{SO}_{4}$ ), filtered and concentrated in vacuum. The crude products were purified by preparative TLC (hexane-ethylacetate). Enantioselectivity was determined by chiral high performance liquid chromatography (HPLC), in comparison with authentic racemic materials.

\subsection{General Procedure for Asymmetric Michael Initiated Ring Closure Reactions}

Unsaturated compound $(0.5 \mathrm{mmol})$, bromomalonate $(0.6 \mathrm{mmol})$, and the crown ether $(5 \mathrm{~mol} \%)$ were dissolved in MTBE, and dry $\mathrm{Na}_{2} \mathrm{CO}_{3}(0.11 \mathrm{~g}, 1 \mathrm{mmol})$ was added. The reaction mixture was stirred at $0{ }^{\circ} \mathrm{C}$ (ice bath). The reaction was monitored by TLC (hexane-ethyl-acetate 4:1). After completion of the reaction, the mixture was filtered, then concentrated. The crude product was purified on silica gel by preparative TLC with hexane:EtOAc (5:1) as eluent. Enantioselectivity was determined by chiral high performance liquid chromatography (HPLC), in comparison with authentic racemic materials.

\subsection{General Procedure for the Catalyst Recycling}

After the reactions were complete, $7 \mathrm{ml} \mathrm{MTBE}$ and $3 \mathrm{ml}$ water was added to the reaction mixture and the phases were separated. Then the catalyst was extracted with $5 \times 10 \mathrm{ml}$ $a q . \mathrm{HCl}$ solution $(10 \mathrm{w} / \mathrm{w} \%)$. Solid sodium hydroxide was added to the combined aqueous layers until the $\mathrm{pH}$ turned slightly basic ( $\mathrm{pH} 8-9)$. The liberated crown catalyst was extracted with MTBE $(5 \times 10 \mathrm{ml})$ and the combined organic layers were dried $\left(\mathrm{Na}_{2} \mathrm{CO}_{3}\right)$, filtered then concentrated. The residue was dried in a desiccator.

Acknowledgements Open access funding provided by Budapest University of Technology and Economics (BME). Zsolt Rapi is grateful for the scholarship of the Varga József Foundation. The research reported in this paper has been supported by the National Research,
Development and Innovation Fund (TUDFO/51757/2019-ITM, Thematic Excellence Program).

Open Access This article is distributed under the terms of the Creative Commons Attribution 4.0 International License (http://creativecommons.org/licenses/by/4.0/), which permits unrestricted use, distribution, and reproduction in any medium, provided you give appropriate credit to the original author(s) and the source, provide a link to the Creative Commons license, and indicate if changes were made.

\section{References}

1. Dehmlow EV, Dehmlow SS (1993) Phase Transfer Catalysis. $\mathrm{VCH}$, Weinheim

2. Starks CM, Liotta CL, Halpern M (1994) Phase-Transfer Catalysis. Chapman \& Hall, New York

3. Sasson Y, Neumann R (1997) Handbook of Phase-Transfer Catalysis. Blackie Academic \& Professional, London

4. Halpern ME (1997) Phase-Transfer Catalysis. American Chemical Society, Washington DC

5. Ooi T, Maruoka K (2007) Angew Chem Int Ed 46:4222

6. Marouka K (2008) Asymmetric Phase Transfer Catalysis. WileyVCH Verlag GmbH \& Co. KgaA, Weinheim

7. Maruoka K, Shirakawa S (2013) Angew Chem Int Ed 52:4312

8. Kaneko S, Kumatabara Y, Shirakawa S (2016) Org Biomol Chem 14:5367

9. Chinchilla R, Mazón P, Nájera C (2000) Tetrahedon 11:3277

10. Thierry B, Perrard T, Audouard C, Plaquevent JC, Cahard D (2001) Synthesis 11:1742

11. Chinchilla R, Mazoón P, Nájera C (2004) Adv Synth Catal 346:1186

12. Shi Q, Lee YJ, Kim MJ, Park MK, Lee K, Song H, Cheng M, Jeong BS, Park HG, Jew SS (2008) Tetrahedron Lett 49:1380

13. Itsuno S, Paul DK, Ishimoto M, Haraguchi N (2010) Chem Lett 39:86

14. Parvez M, Haraguchi N, Itsuno S (2012) Org Biomol Chem 10:2870

15. Izquierdo J, Ayats $\mathrm{C}$, Henseler AH, Pericàs MA (2015) Org Biomol Chem 13:4204

16. Hassan M, Haraguchi N, Itsuno S (2016) J Polym Sci A 1(54):621

17. Shirakawa, S Tanaka Y, Maruoka K (2004) Org Lett 9:1429

18. Tarí S, Avila A, Chinchilla R, Nájera C (2012) Tetrahedron 23:176

19. Schettini R, Sicignano M, De Riccardis F, Izzo I, Della Sala G (2018) Synthesis 50:4777

20. Cram DJ, Sogah GDY (1981) J Chem Soc Chem Commun 625

21. Pham TS, Czirok JB, Balázs L, Pál K, Kubinyi M, Bitter I, Jászay Z (2011) Tetrahedron 22:480

22. Alonso-López M, Martín-Lomas M, Penadés S (1986) Tetrahedron Lett 27:3551

23. van Maarschalkerwaart DAH, Willard NP, Pandit UK (1992) Tetrahedron 48:8825

24. Kanakamma PP, Mani NS, Maitra U, Nair V (1995) J Chem Soc Perkin Trans 1:2339

25. Tőke L, Bakó P, Keserű GM, Albert M, Fenichel L (1998) Tetrahedron 54:213

26. Jarosz S, Listkowski A (2006) Curr Org Chem 10:643

27. Yonezawa K, Patil ML, Sasai H, Takizawa S (2005) Heterocycles 66:639

28. Aoki S, Sasaki S, Koga K (1989) Tetrahedron Lett 30:7229

29. Dehmlow EV, Knufinke V (1992) Liebigs Ann Chem 283

30. Allwood BL, Shahriari-Zavareh H, Stoddart JF, Williams DJ (1984) J Chem Soc 22:1461 
31. Shahriari-Zavareh H, Stoddart JF, Williams MK (1985) J Inclusion Phenom 3:355

32. Bakó P, Rapi Z, Keglevich G (2015) Period Politech Chem 59:51

33. Bakó P, Keglevich G, Rapi Z (2010) Lett Org Chem 7:645

34. Rapi Z, Démuth B, Keglevich G, Grün A, Drahos L, Sóti PL, Bakó $P$ (2014) Tetrahedron 25:141

35. Rapi Z, Grün A, Keglevich G, Stirling A, Bakó P (2016) New J Chem 40:7856

36. Rapi Z, Nemcsok T, Pálvölgyi Á, Keglevich G, Grün A, Bakó P (2017) Chirality 6:257

37. Rapi Z, Nemcsok T, Grün A, Pálvölgyi Á, Samu G, Hessz D, Kubinyi M, Kállay M, Keglevich G, Bakó P (2018) Tetrahedron $74: 3512$

38. Luo H, Dai S, Bonnesen PV (2004) Anal Chem 76:2773

39. Okano K (2011) Tetrahedron 67:2483

40. Yamashita J, Minagawa M, Sonobe A, Ohashi S, Kawamura M, Shimizu K, Hashimoto H (1982) Chem Lett 1409

41. Di Cesare P, Gross B (1979) Synthesis 458

42. Gatto VJ, Gokel GW (1984) J Am Chem Soc 106:8240

43. Rapi Z, Bakó P, Drahos L, Keglevich G (2015) Heteroatom Chem 26:63

44. Pham TS, Rapi Z, Bakó P, Petneházy I, Stirling A, Jászay Z (2017) New J Chem 41:14945

45. Lauret C (2001) Tetrahedron 12:2359

46. Schneider C (2006) Synthesis 3919

47. B. Das, K. Damodar, in: Heterocycles in Natural Product Synthesis, ed by K.C. Majumdar, S.K. Chattopadhyay, (Wiley-VCH, Weinheim, 2011), pp. 3, 63

48. Miyashita K, Imanishi T (2005) Chem Rev 105:4515

49. Zhu Y, Wang Q, Cornwall RG, Shi Y (2014) Chem Rev 114:8199

50. De Faveri G, Ilyashenko G, Watkinson M (2011) Chem Soc Rev 1722

51. Julia S, Masana J, Vegal JC (1980) Angew Chem Int Ed 9:929

52. Bérubé C, Barbeau X, Lagüe P, Voyer N (2017) Chem Commun 53:5099

53. Tsogoeva SB, Wöltinger J, Jost C, Reichert D, Kühnle A, Krimmer HP, Drauz K (2002) Synlett 707

54. Colonna S, Molinari H, Banfi S, Juliá S, Masana J, Alvarez A (1983) Tetrahedron 39:1635

55. Itsuno S, Sakakura M, Ito K (1990) J Org Chem 55:6047

56. Geller T, Roberts SM (1999) J Chem Soc Perkin Trans 1:1397

57. Liu X, Li Y, Wang G, Chai Z, Wua Y, Zhao G (2006) Tetrahedron $17: 750$
58. Makó A, Rapi Z, Keglevich G, Szöllősy Á, Drahos L, Hegedûs L, Bakó P (2010) Tetrahedron 21:919

59. Marsman B, Wynberg H (1979) J Org Chem 44:2312

60. Ryukichi T, Shahnaz B, Akiko S, Arata Y, Kin-ichirou K, Katsuo O (2004) Heterocycles 64:129

61. Julia S, Guixer J, Masana J, Rocas J, Colonna S, Annuziata R, Molinari H (1982) J Chem Soc Perkin Trans 1:1317

62. Liu Y, Provencher BA, Bartelson KJ, Deng L (2011) Chem Sci 2:1301

63. Donaldson WA (2001) Tetrahedron 57:8589

64. Faust R (2001) Angew Chem 113:2312

65. Pietruszka J (2003) Chem Rev 103:1051

66. Chen DYK, Pouwer RH, Richard JA (2012) Chem Soc Rev 41:4631

67. T. Hudlicky, J.W. Reed, in Comprehensive Organic Synthesis, vol. 5, ed. by B.M. Trost, I. Fleming (Pergamon, Oxford. 1991), p. 899

68. Cavitt MA, Phun LH, France S (2014) Chem Soc Rev 43:804

69. Schneider TF, Kaschel J, Werz DB (2014) Angew Chem Int Ed 53:5504

70. Lebel H, Marcoux JF, Molinaro C, Charette AB (2003) Chem Rev 103:977

71. Pellissier H (2008) Tetrahedron 64:7041

72. Bartoli G, Bencivenni G, Dalpozzo R (2014) Synthesis 46:979

73. Arai S, Nakayama K, Ishida T, Shioiri T (1999) Tetrahedron Lett 40:4215

74. Del Fiandra C, Piras L, Fini F, Disetti P, Moccia M, Adamo MFA (2012) Chem Commun 48:3863

75. Herchl R, Waser M (2013) Tetrahedron Lett 54:2472

76. Herchl R, Waser M (2014) Tetrahedron 70:1935

77. Rapi Z, Nemcsok T, Grün A, Pálvölgyi Á, Samu G, Hessz D, Kubinyi M, Kállay M, Keglevich G, Bakó P (2018) Tetrahedron $74: 3512$

78. Russo A, Meninno S, Tedesco C, Lattanzi A (2011) Eur J Org Chem 26:5096

79. Pálvölgyi Á, Rapi Z, Ozohanics O, Tóth G, Keglevich G, Bakó P (2018) Res Chem Int 44:1627

80. Aitken LS, Hammond LE, Sundaram R, Shankland K, Brown GD, Cobb AJA (2015) Chem Commun 51:13558

81. Zhang Y, Lin L, Chen Y, Liua X, Feng X (2017) Adv Synth Catal 359:1831

Publisher's Note Springer Nature remains neutral with regard to jurisdictional claims in published maps and institutional affiliations. 